\title{
Evaluation of Quorum-Sensing, Antibiotics Resistance, and Biofilm Formation in Pathogenic Bacteria from the Hospital Environments
}

\author{
Fadhl A. S. Al Gashaa ${ }^{1,2, *}$, Laith B. Alhusseini ${ }^{3}$, Shayma M. A. Al Baker ${ }^{1}$, \\ Mohammed F. AL Marjani ${ }^{4}$, Zahraa A. Khadam ${ }^{4}$, Dunya J. Ridha ${ }^{5}$ and Aws H. Al \\ Rahhal $^{5}$
}

${ }^{1}$ Department of Biology, Al Farabi University College, Baghdad, Iraq; ${ }^{2}$ Department of Medical Microbiology, College of Science, Ibb University, Yemen; Department of Ecology, College of Science, Kufa University, Kufa, Najaf, Iraq; ${ }^{4}$ Department of Biology, College of Science, Mustansiriyah University, Baghdad, Iraq; ${ }^{5}$ Ministry of Higher Education and Scientific Research, Research and Development Department.

Received: October 8, 2020; Revised: December 19, 2020; Accepted: January 7, 2021

\begin{abstract}
Background: Multidrug-resistant bacteria (MDR) often contaminate hospital environment and cause serious illnesses. Quorum Sensing (QS) regulates a variety of downstream cellular processes, including antibiotics resistance mechanisms and biofilm formation, and causes harm to the host. This study investigates antibacterial susceptibility and biofilm formation of pathogenic bacteria in hospital environment.

Methods: Hundred bacterial isolates were collected from various environments in the Medical City hospital. The antimicrobial susceptibility technique was evaluated through disk diffusion method. Next, biofilms formation was detected by the microliter plate assay. Finally, PCR was used to analyze the frequency of QS system genes.

Results: Current findings showed that the predominant isolates were Acinetobacter baumannii (34\%), Escherichia coli (30\%), Pseudomonas aeruginosa (19\%), and Klebsiella pneumonia (17\%). In general, significant resistance was found related to trimethoprim (88\%), Augmentin (88\%), and cefotaxime (72\%). Among all isolates, $62 \%$ of sensitivity was related to ciprofloxacin. Biofilm had been formed by $39 \%$ of isolates. PCR results showed that the frequency of lasI and rhlI gene was $70 \%$ and $61 \%$, respectively.

Conclusion: Current findings revealed that the hospital environment is a potential reservoir of MDR gram-negative pathogenic bacteria. Thus, we suggest that the health policymakers in Iraq must critically apply the guidelines and recommendations for monitoring the environments in the health sector.
\end{abstract}

Keywords: Antibiotics Footprint, Acinetobacter baumannii, Antibiotics Resistance, Quorum-Sensing, PCR.

\section{Introduction}

Nosocomial infections, also known as hospital-acquired infections, are serious global health concerns, mainly occurring during hospitalization and causing increased morbidity and mortality (Labi et al., 2019). A hospital environment is undoubtedly a great source of potentially pathogenic bacteria (Bouzada et al., 2010). It can be contaminated with bacterial pathogens, mainly Gramnegative (G-ve) rods such as Acinetobacter, Escherichia coli, Pseudomonas spp, Klebsiella sp, Shigella spp, Salmonella spp and Proteus spp, and Gram-positive (G+ve) cocci such as Staphylococcus aureus, Enterococcus and Streptococcus. Environmental surfaces serve as a reservoir for pathogenic bacteria (Otter et al., 2013). The development of nosocomial infection depends on a multifaceted relationship between the rate of contamination of the hospital environment, characteristics of the pathogen, and a susceptible host (Worku et al., 2018). Biofilm bacteria can share nutrients and are shielded from harmful environmental factors such as desiccation, antibiotics, and the immune system of a host body (Nirwati et al., 2019). In the hospital environment, biofilm-forming bacteria can associate with the ability to survive on surfaces, resist antibiotics, and face host defenses. Therefore, it contributes to cause chronic infections (Ali et al., 2019).

Quorum sensing are used by pathogenic bacteria to regulate gene expression. QS bacteria produce and release signals called autoinducers molecules (Häussler, 2010). Target genes regulate virulence factors, biofilm formation, and broad behaviors including swarming, swimming, twitching motility, and conjugation (Rutherford and Bassler, 2012). The most common QS system in G-ve bacteria involves the production of $\mathrm{N}$ - acylated homoserine lactones (AHLs) or autoinducer (Netotea et al., 2009). QS signaling will trigger biofilm formation, resulting in antimicrobial resistance of the pathogens, thereby increasing the therapeutic complexity of bacterial diseases (Jiang et al., 2019). In this regard, the main aim of

\footnotetext{
* Corresponding author e-mail: fad974@gmail.com.
} 
the current study is to identify the seriousness of a hospital environment as a potential reservoir of multidrug-resistant bacteria capable of infecting patients.

\section{Materials and Methods}

\subsection{Bacterial isolates collection and identification}

A total of one hundred bacterial isolates were collected from the surfaces, laundries, health care workers, and medical equipment in Medical City hospital in Baghdad, Iraq. Sterile swabs were used for the collected samples. These isolates were identified by routine biochemical tests and the Vitek 2 system.

\subsection{Antibiotic Susceptibility test}

The pattern of antibiotic susceptibility was done by the Kirby-Bauer method and interpreted according to the Clinical Laboratory Standard Institute guidelines (CLSI, 2020). Eight antibiotic discs were used in this study, which

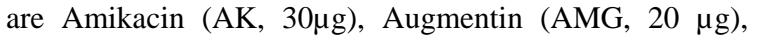

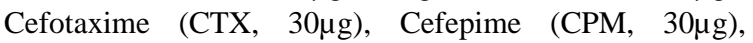

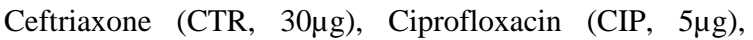

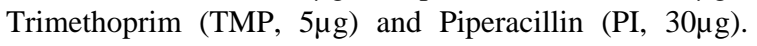
These discs are provided from Bioanalyse in Turkey. The duplicated antibiotic was made and quality controled using P. aeruginosa ATCC 27853 (incubated at $37^{\circ} \mathrm{C}$ for $18-$ 24hr.). Bacterial isolates were resistant to at least three different antimicrobials classes considered as MDR.

\subsection{Biofilm formation assay}

Microliter Plate Assay was performed for biofilm formation according to the method described by Babapour et al. (2016). First, $200 \mu \mathrm{l}$ of bacterial suspension overnight culture (equivalent to $0.5 \mathrm{McF}$ arland standard) was used to inoculate wells of a flat-bottom 96-well polystyrene microtiter plate (Coastar, USA), containing $180 \mu \mathrm{l}$ of Brain Heart Infusion broth (Himedia, India) with $2 \%$ sucrose. After incubation at $37 \mathrm{C}^{\circ}$ for 24 hours, unattached cells were gently rinsed three times with phosphate buffer saline (pH: 7.2). Then, cells were dried at room temperature for $15 \mathrm{~min}$. Later, adherent bacteria Table 1: Primers oligonucleotide sequence and molecular size of PCR products

\begin{tabular}{|c|c|c|c|}
\hline Gene & Oligonucleotide & Product size bp & Reference \\
\hline \multirow{2}{*}{ lasR } & F: 5'-TGCCGATTTTCTGGGAACC-3' & \multirow{2}{*}{401} & \\
\hline & R: 5'-CCGCCGAATATTTCCCATATG-3' & & \\
\hline \multirow{2}{*}{ lasI } & F: 5'-TCGACGAGATGGAAATCGATG-3' & \multirow{2}{*}{402} & \\
\hline & R: 5'-GCTCGATGCCGATCTTCAG-3' & & \\
\hline \multirow{2}{*}{ rhlI } & F: 5'-CGAATTGCTCTCTGAATCGCT-3' & \multirow{2}{*}{182} & (Cotar et al., 2010) \\
\hline & R: 5'-GGCTCATGGCGACGATGTA-3' & & \\
\hline \multirow{2}{*}{ rhlR } & F: 5'-TCGATTACTACGCCTATGGCG-3' & \multirow{2}{*}{208} & \\
\hline & R: 5'-TTCCAGAGCATCCGGCTCT-3' & & \\
\hline
\end{tabular}

\section{Results}

The study aimed to identify the seriousness of hospitals environment as a potential reservoir of multidrug-resistant bacteria and inform policy to monitoring the hospital environment. Thus, the current finding showed that pathogenic bacteria heavily contaminate the surfaces of the hospitals. A hundred of bacterial Gram-negative isolates were identified. Among all isolates, A. baumannii were were fixed with $200 \mu \mathrm{l}$ of $99 \%$ methanol per well. The crystal violate (0.1\%), rewashed, and extracted with $200 \mu \mathrm{l}$ ethanol (95\%). A total of $200 \mu \mathrm{l}$ of the mixed solution was analysis using a spectrophotometer at optical density $\left(\mathrm{OD}_{630}\right) 630 \mathrm{~nm}$ (OPTIMA/Japan). Each assay was performed in triplicate, and the mean $\mathrm{OD}_{630}$ value of tested wells was applied to biofilm-forming ability. Uninoculated medium was considered as negative control. Finally, adherence capabilities of the isolates were divided into four categories, and above the mean optical density of the negative control was considered as the cut-off optical density (ODc). Based on the ODs in brain heart infusion broth, the isolates with OD360 $<$ ODc360 were defined as biofilm non-formers, isolates with (ODc $<$ OD $<2 \times \mathrm{ODc}$ ) were defined as biofilm formers of weak level, isolates with $(2 \times \mathrm{ODc}<\mathrm{OD}<4 \times \mathrm{OD})$ were defined as moderate level, and isolates with $(4 \times \mathrm{OD}<\mathrm{OD})$ were defined as strong level.

\subsection{DNA extraction and gene amplification}

DNA was extracted according to the manufacturer's instructions of the DNA extraction kit (WizPrep ${ }^{\mathrm{TM}}$ gDNA Mini Kit, South Korea). Polymerase Chain Reaction was performed for amplification of lasR, rhlR, lasI and rhlI

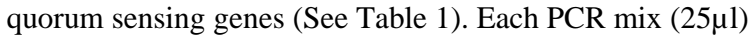
was composed from $12.5 \mu$ l of Go Taq ${ }^{\circledR}$ Green master mix, template DNA $5 \mu$, forward \& reverse primers $(1 \mu$ for each), and $5.5 \mu \mathrm{l}$ of deionized nuclease-free water (Promega, USA).

PCR amplification conditions were as follows (all primers): initial denaturation at $95^{\circ} \mathrm{C} / 5 \mathrm{~min}$ followed by 36 cycles of $95^{\circ} \mathrm{C} / 30 \mathrm{sec}, 59^{\circ} \mathrm{C} / 1 \mathrm{~min}$ and $72^{\circ} \mathrm{C} / 1 \mathrm{~min}$, and a final extension at $72^{\circ} \mathrm{C} / 10 \mathrm{~min}$ (Cotar et al., 2010). The products were analyzed by $1 \%$ gel agarose (Promega, USA), containing $0.5 \mu \mathrm{g} / \mathrm{mL}$ of ethidium bromide and visualized under UV light. bacteria attached to the surface were stained with $200 \mu$ of

$34 \%$, E. coli were $30 \%$, P. aeruginosa were $19 \%$, and $K$. pneumonia were $17 \%$. The results of the antibiotics susceptibility test showed that most isolates were highly resistant against most antibiotics. The highest resistance was recorded for trimethoprim (88\%), Augmentin (88\%), and cefotaxime $(72 \%)$. At the same time, ciprofloxacin (38\%) was recorded as the most effective antibiotic against isolates. All isolates showed resistance to the rest of antibiotics ranging between (44\%) and (66\%), as shown in Figure 1. 


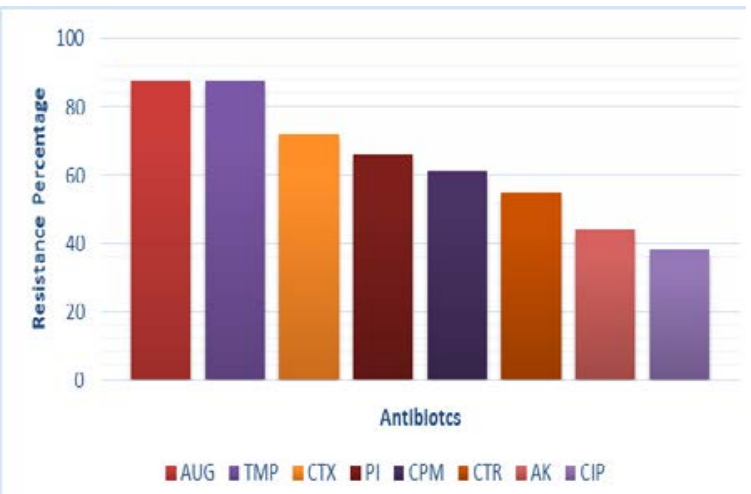

Figure 1: Percentage of Antibiotic susceptibility test of bacterial isolates.

The current obtained results showed that $39 \%$ of the environmental isolates were biofilm producers. The results recorded that four isolates with a percentage of $11.76 \%$ of A. baumannii isolates were strong biofilm producers. At the same time, most isolates were producers with weak biofilm with percentage of $66.66 \%$. In general, $K$. pneumoniae was the high biofilm producers with percentage of $52.94 \%$, followed by E. coli $(43.33 \%)$, A. baumannii (35.29\%), and $P$. aeruginosa (26.32\%) (See Table 2).

Table 2: Adhesion patterns of isolates

\begin{tabular}{|c|c|c|c|c|}
\hline \multirow{2}{*}{ Isolates (Number) } & \multicolumn{3}{|c|}{ Adhesion patterns } & \multirow{2}{*}{ Total (\%) } \\
\hline & Strong & Moderate & Weak & \\
\hline $\begin{array}{c}\text { A. baumannii } \\
(\mathrm{n}=34)\end{array}$ & 4 & Non former & 8 & 12 (35.29\%) \\
\hline E. coli $(\mathrm{n}=30)$ & Non former & 5 & 8 & 13 (43.33\%) \\
\hline $\begin{array}{l}\text { P. aeruginosa } \\
\qquad(\mathrm{n}=19)\end{array}$ & Non former & Non former & 5 & $5(26.32 \%)$ \\
\hline $\begin{array}{l}\text { K. pneumonia } \\
(\mathrm{n}=17)\end{array}$ & Non former & 4 & 5 & $9(52.94 \%)$ \\
\hline Total (\%) & $4(10.26 \%)$ & $9(23.08 \%)$ & $\begin{array}{c}26 \\
(66.66 \%)\end{array}$ & 39 (39\%) \\
\hline
\end{tabular}

PCR analysis revealed that $70 \%$ of isolates carried the lasI gene, $61 \%$ of isolates carried the rhlI gene, $57 \%$ of isolates had the lasR gene, while $4 \%$ isolates carried the rhIR gene (See Figure 2 and Table 3). A. baumannii was the most bacterial isolate harboring quorum sensing genes, lasI, lasR, and rhlI genes found in 25 (73.52\%) isolates, while $4(11.76 \%)$ of isolates carried rhIR gene. The lasI, lasR, and rhlI genes were found in all isolates of $P$. aeruginosa (100\%) and $13(76.43 \%)$ isolates of $K$. pneumonia. Finally, 13 (43.33\%) E. coli isolates contained lasI gene, and 4 (13.33\%) isolates had rhlI genes.
Table 3: Number and percentage of QS genes presence in isolates

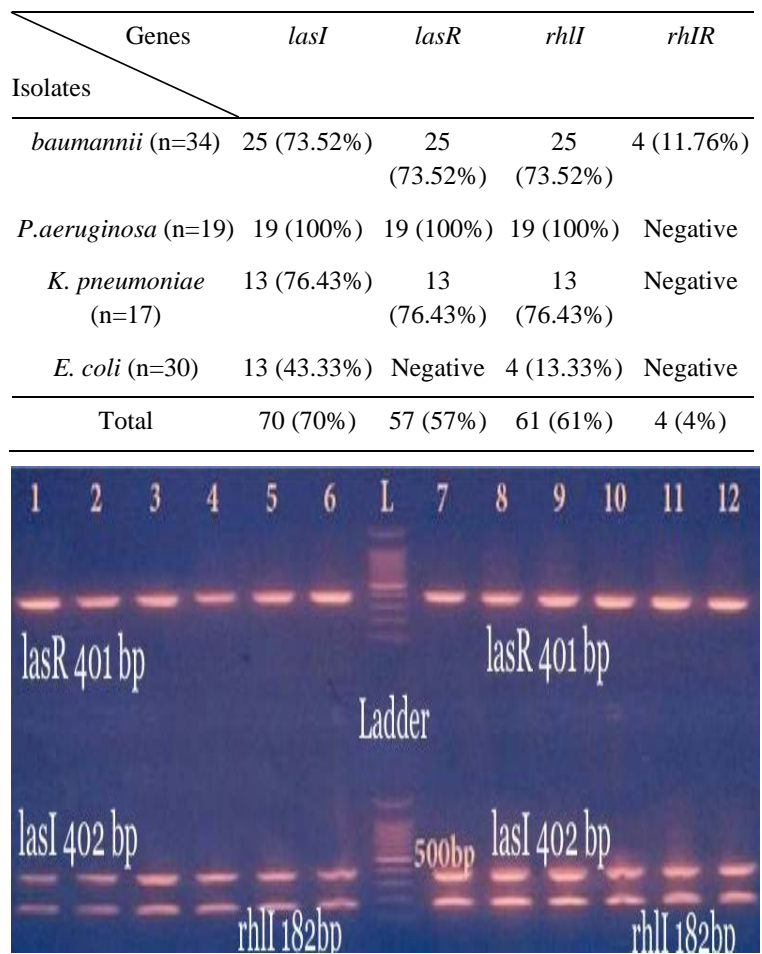

Figure 2: Agarose Gel Electrophoresis (1\% agarose, 5-10 V/cm for $50 \mathrm{~min}$ ) of lasR, lasI, and rhlI genes. Lane L 100 bp DNA Ladder, Lanes 1-12 Represent of Isolates Bands.

\section{Discussion}

Many studies showed that hospitals' environment (surfaces, clothes, air, water, food, waste, and medical devices) harbor bacteria such as Staphylococcus, Enterococcus, A. baumannii, E. coli, P. aeruginosa, and K. pneumonia. Bacterial isolates in the hospital setting are characterized as MDR, not only for the irrational use of antibiotics but also for the presence of antibiotics residues in fluid effluents (Dougnon et al., 2020). Hospitals' environments are characterized by heavy bacterial density (Ory et al., 2016). Antibiotic resistant bacteria pose a significant threat to public health in the hospitals' environment (Osińska et al., 2017).

Our findings are consistent with several previous studies that showed various components of the hospitals' environment could accommodate many pathogenic bacteria. According to Kim and co-workers, the areas around patients are generally contaminated by bacteria. The bacterial contaminantion on surfaces was supported by the formation of biofilms and prolonged survival in the environment (Kim et al., 1981,Talon, 1999, Bertrou et al., 2000). 
Current findings revealed local isolates carrying one or more QS genes. The Iraqi study conducted by Sallman et al. (2018) reported $82.53 \%$ isolates carrying lasI/lasR and rhlI/rhlR genes. Senturk et al. (2012) displayed that $77.7 \%, 88.8 \%, 66.6 \%$, and $77.7 \%$ of isolates were positive for rhIR, rhlI , lasR, and lasI, respectively. QS involves generation, release and detection of extracellular signal molecules called auto-inducers (AI). It regulates behaviors requiring cells to synchronize in order to achieve successful results (Paluch et al., 2020). The QS system facilitates the bacterial population to grow and proliferate in an environment with effective intercellular communication (Subhadra et al., 2016). QS-controlled processes include antibiotic resistance, biofilm formation and virulence (Paluch et al., 2020).

Antibiotic-resistant $A$. baumannii has been represented as one of the most problematic hospitals acquired bacteria. A. baumannii can colonize in the hospital setting, and constitutes a significant problem in intensive care units (Espinal et al., 2012). A. baumannii was isolated from $11 \%(7 / 64)$ of air samples. Hospitals and healthcare settings are regarded as reservoirs of Pseudomonas spp isolates, which are a worldwide health concern due to the increasing development of MDR isolate (Alhusseini et al., 2019). Several therapeutic challenges exist with MDR $P$. aeruginosa due to the limit of effective treatment strategies (Aloush et al., 2006). The presence of pathogenic bacteria in the hospitals' environment poses a significant risk to health. $K$. pneumonia is recognized as an urgent threat to human health because of the emergence of MDR isolates associated with hospital outbreaks and hyper-virulent strains associated with severe community-acquired infections (Holt et al., 2015). Recorded hospital settings showed the highest percentage of $23 \%$ of extendedspectrum $\beta$-lactamase producing $K$. pneumonia (Chaudhry et al., 2019). Biofilm becomes a significant problem in health care (Dewasthale et al., 2018). Bacteria in a biofilm are a protective mechanism to survive in harsh conditions. These bacteria become more resistant to antibiotics; therefore, this biofilm structure represents an important virulence factor (Espinal et al., 2012).

Antibiotics resistance in biofilms is complex and results from contributions of intrinsic, acquired, and adaptive mechanisms. Most notably, biofilm specific features such as the differential expression of multiple gene networks, extracellular matrix, and the metabolic heterogeneity of subpopulations within a biofilm colony are significant contributors to antibiotic resistance (Taylor et al., 2014). P. aeruginosa and K. pneumoniae exhibited strong biofilm-forming ability on hospital clinical laboratory surfaces. Klebsiella spp. was found to persist on dry inanimate surfaces between $2 \mathrm{Hr}$. to 30 months, while the persistence of $P$. aeruginosa was $6 \mathrm{Hr}$. to 16 months (Chen et al., 2020).

\section{Conclusion}

The extracted findings from this study reported the prevalence of gram-negative pathogenic isolates in the hospitals' environment. So, appropriate measures could help reduce pollutants in the hospitals' environment and reduce related serious illnesses. As a result, the current findings recommend the routine screening and disinfection of the hospitals' environment to prevent contamination.

\section{Author's contributions}

Laith B. Alhusseini, Dunya J. Ridha, Zahraa A. Khadam: Conceptualization, Design of methodology. Mohammed F. Al Marjani: Supervision, Validation. Laith B. Alhusseini, Zahraa A. Khadam: Writing-Reviewing and Editing. Fadhl A. S. Al Gasha, Shayma M. A. Al Baker, Awas H. Al Rahal: Writing and Reviewing the manuscript.

\section{Ethical approval}

The authors do not see any ethical issues that may arise after the publication of this manuscript.

\section{Acknowledgements}

We thank the clinical staff of the Medical City hospital in Baghdad. We are grateful for the useful comments and suggestions from anonymous referees.

\section{Conflict of interest}

The authors declare that they have no conflict of interest in the publication.

\section{References}

Alhusseini LB, Maleki A, Kouhsari E, Ghafourian S, Mahmoudi M and Al Marjani MF. 2019. Evaluation of type II toxin-antitoxin systems, antibiotic resistance, and biofilm production in clinical MDR Pseudomonas aeruginosa isolates in Iraq. Gene Reports, 17: 100546.

Ali FS, Authman SH and Al-Marjani MF. 2019. Imipenem Resistance and Biofilm Formation In Klebsiella pneumoniae from some Hospitals in Baghdad City. J Pharm Sci Res., 11: 233-238.

Aloush V, Navon-Venezia S, Seigman-Igra Y, Cabili S and Carmeli Y. 2006. Multidrug-resistant Pseudomonas aeruginosa: risk factors and clinical impact. Antimicrob Agents Chemother., 50: $43-48$.

Babapour E, Haddadi A, Mirnejad R, Angaji S and Amirmozafari N. 2016. Biofilm formation in clinical isolates of nosocomial Acinetobacter baumannii and its relationship with multidrug resistance. Asian Pac J Trop Biomed., 6: 528-533.

Bertrou A, Chapuis C and Hajjar J. 2000. Relations entre contamination et environnement hospitalier. Hygiènes (Lyon), 8 (3): 143-146.

Bouzada ML, Silva VL, Moreira FA, Silva GA and Diniz CG. 2010. Antimicrobial resistance and disinfectants susceptibility of persistent bacteria in a tertiary care hospital. $J$ Microbiol Antimicrob., 2: 105-112.

Chaudhry TH, Aslam B, Arshad MI, Nawaz Z and Waseem M. 2019. Occurrence of ESBL-producing Klebsiella pneumoniae in hospital settings and waste. Pak J Pharm Sci., 32(2):773-778.

Clinical and Laboratory Standards Institute. 2020. Performance standards for antimicrobial susceptibility testing, 30th ed CLSI supplement M100 CLSI., Wayne, PA.

Cotar AI, Chifiriuc MC, Dinu S, Pelinescu D, Banu O and Lazăr V. 2010. Quntitative real-time PCR study of the influence of probiotic culture soluble fraction on the expression of pseudomonas aeruginosa quorum sensing genes. J Arc Microbial. Immunol., 69(4):213-223.

Dewasthale S, Mani I and Vasdev K. 2018. Microbial biofilm: current challenges in health care industry. J Appl Biotechnol Bioeng., 5: 156-160. 
Dougnon VT, Koudokpon H, Chabi Y, Fabiyi K, Legba B, Dougnon j and Baba-Moussa L. 2020. Infection Risks and Antimicrobial Resistance in Tertiary Hospitals in Benin: Study Cases of Sakété-Ifangni and Menontin Hospitals. Int J Infect., 7(1):e99649.

Espinal P, Marti S and Vila J. 2012. Effect of biofilm formation on the survival of Acinetobacter baumannii on dry surfaces. $J$ Hosp Infect., 80(1): 56-60.

Häussler S. 2010. Multicellular signalling and growth of Pseudomonas aeruginosa. Int J Med Microbiol., 300(8): 544-548.

Holt KE, Wertheim H, Zadoks RN, Baker S and et al. 2015. Genomic analysis of diversity, population structure, virulence, and antimicrobial resistance in Klebsiella pneumoniae, an urgent threat to public health. Proc Natl Acad Sci., 112: E3574-E3581.

Jiang Q, Chen J, Yang C, Yin Y and Yao K. 2019. Quorum sensing: a prospective therapeutic target for bacterial diseases. Biomed Res Int., 7:1-15.

Kim KH, Fekety R, Batts DH, Brown D, Cudmore M, Silva J and Waters D. 1981. Isolation of Clostridium difficile from the environment and contacts of patients with antibiotic-associated colitis. J Infect Dis., 143(1): 42-50.

Labi, AK. Obeng-Nkrumah N, Owusu E, Bjerrum S and et al. 2019. Multi-centre point-prevalence survey of hospital-acquired infections in Ghana. J Hosp Infect., 101(1): 60-68.

Chen Lh, Li Y, Qi Y and et al. 2020. Evaluation of a pulsed xenon ultraviolet light device for reduction of pathogens with biofilmforming ability and impact on environmental bioburden in clinical laboratories. Photodiagnosis Photodyn Ther., 29: 101544.

Netotea S, Bertani I, Steindler L, Kerényi A, Venturi V and Pongor S. 2009. A simple model for the early events of quorum sensing in Pseudomonas aeruginosa: modeling bacterial swarming as the movement of an" activation zone". Biol Direct., 4(1): 1-16.

Nirwati H, Sinanjung K, Fahrunissa F and et al. 2019. Biofilm formation and antibiotic resistance of Klebsiella pneumoniae isolated from clinical samples in a tertiary care hospital, Klaten, Indonesia. BMC proceedings., 13(11): 1-8.

Ory j, Bricheux G, Togola A, Bonnet JL, Donnadieu-Bernard F, Nakusi L, Forestier Ch and Traore O. 2016. Ciprofloxacin residue and antibiotic-resistant biofilm bacteria in hospital effluent. Environ Pollut., 214: 635-645.
Osińska A, Korzeniewska E, Harnisz M and Niestępski S. 2017. The prevalence and characterization of antibiotic-resistant and virulent Escherichia coli strains in the municipal wastewater system and their environmental fate. Sci Total Environ., 577: 367-375.

Otter JA, Yezli S, Salkeld JA and French GL. 2013. Evidence that contaminated surfaces contribute to the transmission of hospital pathogens and an overview of strategies to address contaminated surfaces in hospital settings. Am J Infect Control., 41(5): S6-S11.

Paluch E, Rewak-Soroczyńska J, Jędrusik I, Mazurkiewicz E and Jermakow K. 2020. Prevention of biofilm formation by quorum quenching. Appl Microbiol Biotechnol., 104: 1871-1881.

Rutherford ST and Bassler BL. (2012). Bacterial quorum sensing: its role in virulence and possibilities for its control. Cold Spr Harbor perspectives med., 2(11): a012427.

Sallman R, Hussein S and Ali M. 2018. ERIC- PCR Typing, RAPD-PCR Fingerprinting and Quorum Sensing Gene Analysis of Pseudomonas aeruginosa Isolated from Different Clinical Sources. Al-Mustansiriyah J Sci., 29(2): 50-62.

Senturk S, Ulusoy S, Bosgelmez-Tinaz G and Yagci A. 2012. Quorum sensing and virulence of Pseudomonas aeruginosa during urinary tract infections. J Infec Develop Count., 6(06): 501-507.

Subhadra B, Oh MH and Choi CH. 2016. Quorum sensing in Acinetobacter: with special emphasis on antibiotic resistance, biofilm formation and quorum quenching. AIMS Microbiol., 2(1): 27-41.

Talon D. 1999. The role of the hospital environment in the epidemiology of multi-resistant bacteria. J Hosp Infec., 43(1): 1317.

Taylor PK, Yeung AT and Hancock RE. 2014. Antibiotic resistance in Pseudomonas aeruginosa biofilms: towards the development of novel anti-biofilm therapies. J. Biotechnol., 191: 121-130.

Worku T, Derseh D and Kumalo A. 2018. Bacterial profile and antimicrobial susceptibility pattern of the isolates from stethoscope, thermometer, and inanimate surfaces of Mizan-Tepi University Teaching Hospital, Southwest Ethiopia. Int $J$ Microbiol., 2018: ID 9824251, 7 pages. 